Sergiy Varvarenko ${ }^{1}$, Ihor Tarnavchyk ${ }^{1,2}$, Andriy Voronov ${ }^{2}$, Nataliia Fihurka ${ }^{1}$, Iryna Dron ${ }^{1}$, Nataliia N osova ${ }^{1}$, Roman Taras ${ }^{1}$, Volodymyr Samaryk ${ }^{1}$ and Stanislav Voronov ${ }^{1}$

\title{
SYN THESIS AN D COLLOIDAL PROPERTIES OF POLYESTERS BASED ON GLUTAMIC ACIDS AND GLYCOLS OF DIFFERENT NATURE
}

\author{
${ }^{1}$ Lviv Polytechnic National University, \\ 12, Bandera str., 79013 Lviv, Ukraine; 203lab@polynet.Iviv.ua \\ 2N orth Dakota State University, Dept. 2760, P.O. Box 6050, Fargo, N D 58108-6050, USA
}

Received: November 28, 2013 / Revised: February 06, 2013 / Accepted: March 25, 2013

(C) Varvarenko S., Tarnavchyk I., Voronov A., Fihurka N., Dron N., Nosova N., Taras R., Samaryk V., Voronov S., 2013

\begin{abstract}
The paper describes synthesis and colloidal properties of novel $\alpha$-amino acid based polyesters with controllable hydrophilic-lipophillic balance. Polyesters based on glutamic acid and glycols of different nature were obtained via low-temperature activated polyesterification. Such polymers are able to form micellar structures in self-stabilized water dispersion. Peculiarities of Steglich rection in the case of polyesterefication and side processes were established and optimal conditions for polyester synthesis were determined.
\end{abstract}

Keywords: pseudo-poly(amino acid), Steglich esterefication, surface tension, drug delivery system

\section{Introduction}

Biodegradable and biocompatible polymer materials with non-toxic degradation products are widely used for different biomedical applications [1-4]. Hereby, development of new synthesis methods thereof becomes important scientific task.

There are a number of works dedicated to the study of different synthesis techniques for $\alpha$-amino acid and polyethylene glycols (PEGs) based esters synthesis [5-8] including esters of PEGs with glutamic acid (Glu) [9]. Recently, new method of esterification developed by W. Steglich has attracted increasing interest of scientists as a simple and convenient method for ester groups formation under mild conditions, including ester groups between $\alpha$-amino acids and PEG.

Polyesters based on dicarboxylic $\alpha$-amino acids and PEG or polypropylene glycols (PPGs) named "pseudo-poly(amino acids)" are of great interest to scientists. In spite of it, there is no reports about pseudopoly(amino acid) synthesis via irreversible polycondensation such as Steglich esterification.
In this work we present the results of the study of polyester type pseudo-poly(amino acids) synthesis. Glu and its derivatives with protected amino groups (Glu(A)) were used as dicarboxylic acids, and PEGs or PPGs of different molecular weight - as diols in polycondensation.

\section{Experimental}

\subsection{M aterials}

$N$-stearoyl-L-glutamic acid Glu(St) was synthesized in accordance with the following method. $41.05 \mathrm{~g}$ of glutamic acid in $120 \mathrm{ml}$ of water and $279 \mathrm{ml}$ of $2 \mathrm{~N} \mathrm{NaOH}$ were loaded into four-neck reactor equipped with a stirrer. After complete dissolution of glutamic acid, the reactor was warmed to $303 \mathrm{~K}$ and $280 \mathrm{ml}$ of acetone was added. Then $88 \mathrm{~g}$ of stearoyl chloride and $140 \mathrm{ml}$ of $2 \mathrm{~N} \mathrm{NaOH}$ were dripped simultaneously into the reactor to provide $\mathrm{pH}$ of reaction mixture in the range of 10-11. After complete reagent dripping synthesis was treated at the same temperature for $2 \mathrm{~h}$. Then $32 \mathrm{~g}$ of concentrated $\mathrm{HCl}$ in $60 \mathrm{ml}$ of water were added. After $3 \mathrm{~h}$ acidic reaction mixture was filtered on the Buchner funnel and washed with hydrochloric acid water solution (with $\mathrm{pH}=1$ ). Wet crystals of $\mathrm{N}$-stearoyl-L-glutamic acid were obtained. To purify $\mathrm{Glu}(\mathrm{St})$ dried crystals were washed with acetone or hexane. Purity of the obtained N-stearoylL-glutamic acid made 98-99\% (according to the acid value).

N-trifluoroacetyl-L-glutamic acid Glu(TFA) was synthesized using the developed technique. $9.37 \mathrm{~g}$ of dried glutamic acid were loaded into the reactor and $26.67 \mathrm{~g}$ of trifluoroacetic anhydride were slowly added using drop funnel. After complete dissolution of glutamic acid, the reactor was warmed to $303 \mathrm{~K}$ and kept at this temperature 
for $2 \mathrm{~h}$. Then trifluoroacetic anhydride excess and trifluoroacetic acid were distilled off in vacuum atmosphere at $323 \mathrm{~K}$. Prior to using Glu(TFA) was crystallized in the following way: to $1 \mathrm{~g}$ of obtained viscous liquid 3-4 $g$ of water were added. The suspension was filtered and the precipitate was dried in vacuum atmosphere over $\mathrm{P}_{2} \mathrm{O}_{5}$. Purity of the obtained N-stearoylL-glutamic acid made 98-99\% (according to the acid value).

$N$-tert-butoxycarbonyl-L-glutamic acid Glu(Boc) was synthesized using the procedure described in [10].

Polyester synthesis was carried out in accordance with the developed method. First glutamic acid derivative (Glu(A)) (10 mmol), glycol or mixture of two different glycols $(11 \mathrm{mmol})$ and solvent (benzene, dichloromethane or mixture dimethylformamide/dichloromethane depending on the Glu(A) nature) were loaded into reactor. Than DCC (21 mmol) and catalyst - 4-dimethylaminopyridine (DMAP) (1.25 mmol) in solution were added using drop funnel at the temperature of $280 \mathrm{~K}$. After that the reaction mixture was treated for $3 \mathrm{~h}$ at $288 \mathrm{~K}$ and $3 \mathrm{~h}$ at $308 \mathrm{~K}$. Finally a side product of the reaction dicyclohexylurea (DCU) was filtered off and the reaction mixture was evaporated. The structure of the obtained polyesters was confirmed by NMR- and IR-spectroscopy.

\subsection{Analysis}

IR spectroscopic studies were carried out in $\mathrm{KBr}$ pellets or in thin layer using Thermo Scientific Nicolet 8700 spectrometer. ${ }^{1} \mathrm{H}$ NMR spectra of polymers were recorded using JEOL's ECA Series Nuclear Magnetic Resonance (NMR) Spectrometer in automatic conditions of scanning. Mass-spectroscopic studies were conducted on Bruker Daltonics BioToF High-Resolution Mass Spectrometer. Diameter and $\zeta$-potential of the particles were measured using Zeta Sizer Nano-ZS90 (Malvern). Molecular weight of the obtained polymers was determined via gel penetrative chromatography on Waters Corporation chromatograph.

Surface tension of pseudo-poly(amino acid) water solutions was measured at $293 \mathrm{~K}$ using Du Noüy ring method. The critical micelle concentration (CMC) was determined using surface tension isotherms of corresponding polymers [11].

\section{Results and Discussion}

In general, polyester synthesis via Steglich esterification is presented in Fig. 1.

Polyester formation takes place due to the nucleophilic attack of PEG (PPG) hydroxyl group on the
N,N'-dicyclohexylcarbodiimide-activated carboxyl group. It is known that amino group is stronger nucleophil than primary hydroxyl group of PEG or PPG. Therefore, the side reaction of peptide bond formation may occur in the presence of $\alpha$-amino acid with non-protected amino group affecting polyester formation. B. Lele et al. [12] reported that amino acid hydrochlorides prevent nucleophilic attack of amino group on the DCC-activated carboxyl group. Our experiments showed that hydrochloride form substantially decreases amino group nucleophilicity but does not provide sufficient amino group protection. However, complete suppression of amino group attack could not be achieved with hydrochloride protection, thus simultaneous ester bond formation occurs. Estimated quantity of peptide bonds can reach $30 \%$. In the case of low molecular esters synthesis [12] it may lead to the decreasing of the end product yield, however, in polyester synthesis formation of the peptide bond is inadmissible. Therefore, we used a number of glutamic acid $\mathrm{N}$-derivatives in polyester synthesis via Steglich esterification instead of glutamic acid (or its hydrochloride) including: N-tert-butoxycarbonyl-L-glutamic acid Glu(Boc), N-trifluoroacetyl-Lglutamic acid Glu(TFA), N-acetyl-L-glutamic acid Glu(Ac), N-lauroyl-L-glutamic acid Glu(L), N-stearoyl-Lglutamic acid $\mathrm{Glu}(\mathrm{St})$ and N-phtaloyl-L-glutamic acid Glu(Pht).

In N-tert-butoxycarbonyl-L-glutamic acid Glu(Boc) and N-trifluoroacetyl-L-glutamic acid Glu(TFA) amino groups are protected by standard protecting groups which are widely used in peptide synthesis. These protective groups allow to be deprotected under mild conditions with no polyester backbone degradation. Deprotection of $\mathrm{Glu}(\mathrm{Ac})$ and $\mathrm{Glu}(\mathrm{Pht})$ cannot be conducted under mild conditions and these protected glutamic acids were used only for the study of the impact of protecting group on polyester synthesis. On the other hand $\mathrm{Glu}(\mathrm{St})$ and $\mathrm{Glu}(\mathrm{L})$ may serve as a hydrophobic blocks as they contain long alkyl chains. Polycondensation of these hydrophobic acids with PEGs allow to create unique polyester type pseudo-poly(amino acid)s with apparent surface active properties and ability of selfassembly forming supramolecular structures.

Conducted experiments showed that polyesters based on the dicarboxylic acids with protected amino groups and glycols (polyoxyethylene, polyoxypropilene glycol) may be synthesized via Steglich esterification reaction.

The NMR-spectrum of product based on $\mathrm{N}$-stearoyl-L-glutamic acid and dipropylene glycol (Glu(St)-DPG) in deuterated benzene is shown in Fig. 2. Integrals of protons of oxypropylene fragment and protons of alkyl chain were calculated from the spectra confirming estimated polyester composition. 


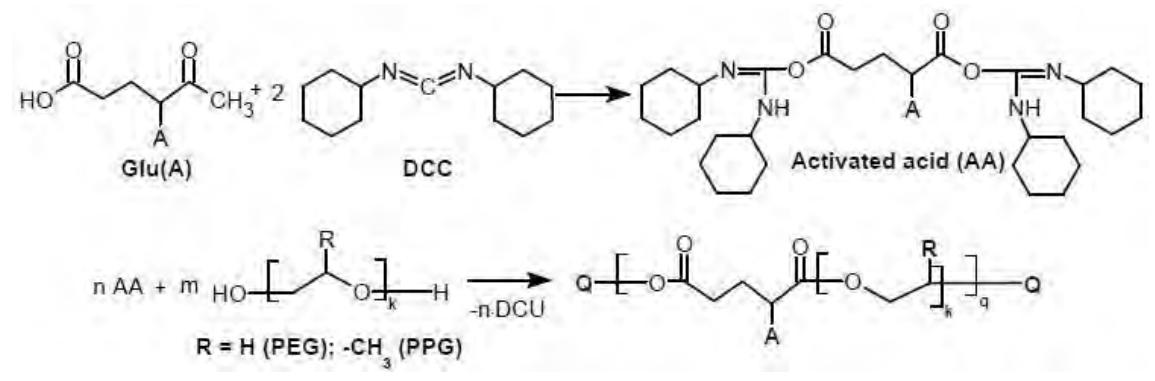

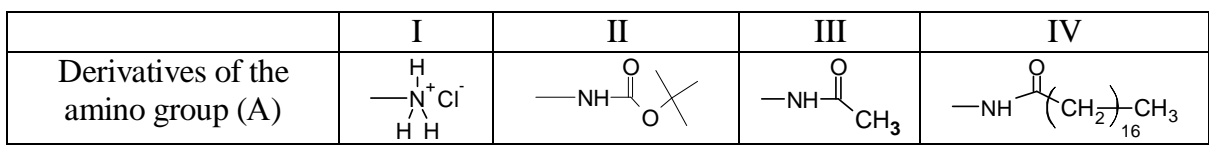

\begin{tabular}{|c|c|c|}
\hline & $\mathrm{V}$ & $\mathrm{VI}$ \\
\hline $\begin{array}{c}\text { Polymer terminal groups } \\
(\mathrm{Q})\end{array}$ & $-\mathrm{CH}_{2}^{-\mathrm{CH}_{2}}-\mathrm{OH}$ & \\
\hline
\end{tabular}

Fig. 1. Mechanism of Steglich esterification of glutamic acid (or its derivatives) and glycols

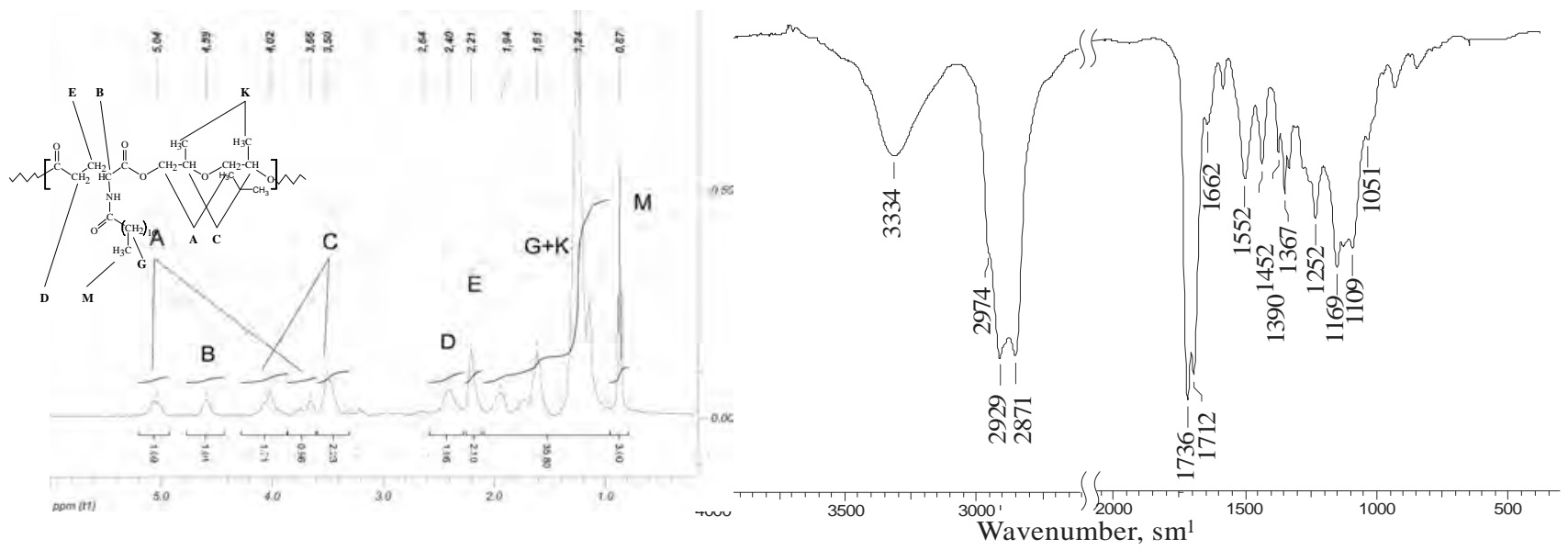

Fig. 2. NMR-spectrum of polyester based on N-stearoyl-L-glutamic acid and dipropylene glycol (Glu(St)-DPG) in deuterated benzene (a) and IR-spectra of polyester based on N-tert-butoxycarbonyl-L-glutamic acid and polyethylene glycol (b)

(average $M W 300)$ (Glu(Boc)-PEG300)

Character absorption band of ester groups $\left(1736 \mathrm{sm}^{-1}\right)$ in IR-spectra (Fig. 2) of Glu(Boc)-PEG300 copolymer confirms polyester formation.

\subsection{Synthesis of Polyesters Based on Glu- tamic Acid and Glycols of Different $N$ ature}

In conventional polycondensation process an average polycondensation degree depends on the dicarboxylic acid and glycol ratio and polycondensation depth. The dependence of the polycondensation degree on these parameters is represented by the Carothers equation:

$$
\bar{s}=\frac{1+r}{1+r-2 r x}
$$

where $r$ - reagent ratio; $x$ - polycondensation depth (conversion).

One can observe that except reagent ratio and polycondensation depth other factors have considerable influence on polycondensation degrees in Steglich esterification of dicarboxylic $\alpha$-amino acids with polyoxyethylene- and polyoxypropylene glycols.

The values of polycondensation degrees at different reagent ratios and synthesis conditions are listed in the Table 1. Molecular masses presented in the column 11 were determined using gel-penetrating chromatography. Polycondensation degrees presented in the column 12 were estimated using polyesters molecular masses. DCU yields in the column 10 were obtained via gravimetric method. 
The rating was conducted according to the precipitated DCU against the loaded acid, not DCC. The last was loaded in a small excess; hence DCU yield calculation against loaded DCC is not correct. Presented DCU yield values should be considered as maximal. Experiments showed that major part (up to $80 \%$ ) of DCU is precipitated during $30 \mathrm{~min}$ and the rest during $2 \mathrm{~h}$ at $288 \mathrm{~K}$. The further extension of the reaction time does not lead to the DCU yield increase. It should be noted that DCU yield in most experiments makes $98 \%$. Such yield should provide sufficiently close polycondensation degree to the theoretically possible value. Calculated values of the polycondensation degree according to Eq. (1) and polycondensation degree by DCU yields are presented in column 13 of the Table 1. Assuming complete conversion, which is dependent only on monomers ratios, comparative polycondensation degrees were calculated using the same equation (Table 1, column 14). By comparing data in the Table 1, one can observe that experimental polycondensation degrees are always lower than polycondensation degrees calculated according to Eq. (1) by the DCU yield. It points on the processes during reaction which lead to the DCU precipitation but do not increase polycondensation degrees.
In addition, DCU yield has been significantly decreased under certain conditions. It could reach 80 $95 \%$ and even $50-60 \%$ in some cases. Therefore, decrease of experimental polycondensation degree is observed. However, conducted studies showed that decrease of DCU yield cannot be attributed to the lack of DCC activation. A number of experiments in the conditions of decreased DCU yields were carried out. In these experiments reaction mixture was treated by acidified water with following DCU precipitation and filtration. Thus non-reacted DCC was converted to DCU and measured. But experiments confirmed that even the additional precipitated amount of DCU does not provide its sufficient material balance. In the most cases the total amount of precipitated DCU was significantly less comparing to calculated equivalent value. It indicates that in the studied reaction a number of processes lead to the DCC consumption but not to its conversion into DCU. Additional studies of polyesters synthesized in conditions of dicarboxylic acid excess and low DCU yield showed significantly lower amounts of terminal carboxyl groups in comparison with expected values calculated using polycondensation degrees.

Table 1

Polycondensation degree values in subject to the reagent ratio and synthesis conditions

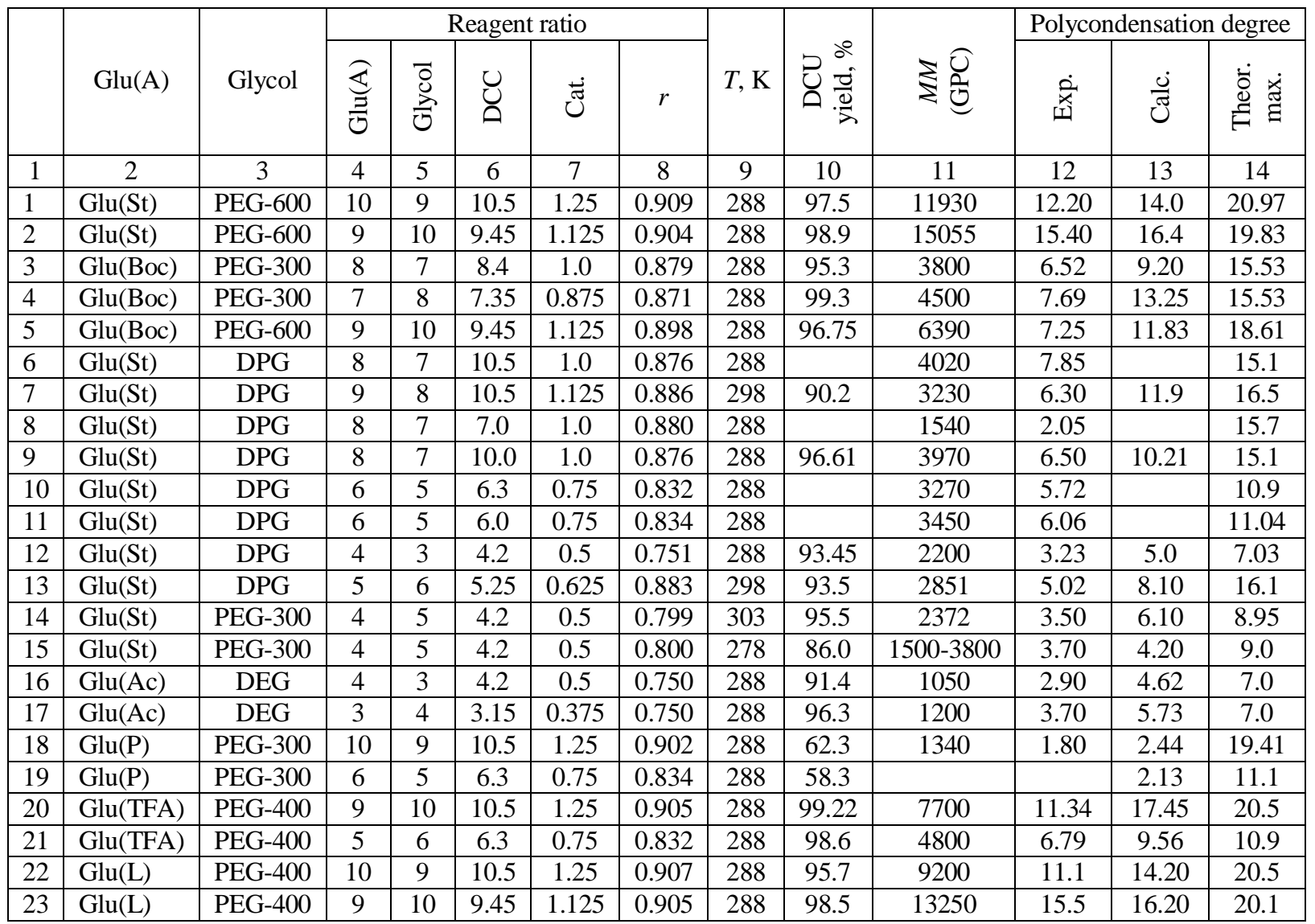


It can be seen from the data presented in Table 1 that polycondensation degree makes $10-80 \%$ of maximum possible values calculated according to the Carothers equation.

The data shown in Fig. 3 allow conveniently evaluate the impact of different parameters on the polycondensation process using the ratio $\left(V_{e / m}\right)$ of experimentally determined polycondensation degree to the maximal theoretical value at the certain diol/acid ratio.

Fig. 3 shows the effect of the reagent nature on $V_{e / m}$ value in the conditions of the monomer excess. One can observe that excess of glycol provides increase of polycondensation degree on $20-50 \%$ for all studied objects. It allows to draw a conclusion that this type of polycondensation should be carried out in the conditions of glycol excess.

The effect of the temperature on the polycondensation process is shown in Fig. 4. Together with the $V_{e / m}$ value this figure shows the ratio $\left(V_{e / u}\right)$ between experimentally determined polycondensation degree (Table 1, column 12) and polycondensation degree calculated by Eq. (1) considering DCU conversion (Table 1, column 13). This ratio particularly allows to characterize processes leading to DCC consumption without DCU release. It can be seen that the temperature increase above $288 \mathrm{~K}$ in all cases leads to $V_{e / m}$ decreasing indicating that higher temperature does not promotes achieving higher polycondensation degrees. Moreover, as temperature rises the $V_{e / u}$ value tends to increase. It indicates that the part of processes which do not promote the second stage of the reaction according to Scheme 1 is being increased under increased temperatures. On the other hand, temperature decrease below $288 \mathrm{~K}$ does not lead to increasing of the polycondensation degree as well. In Fig. 3 it is shown by the lowering of the

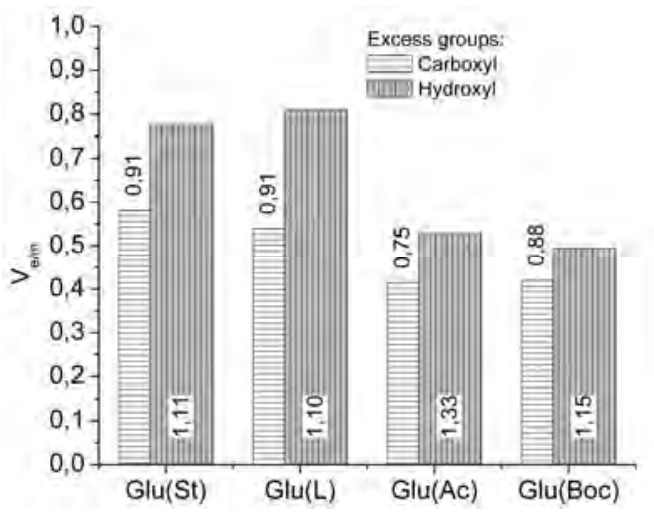

Fig. 3. The ratio $\left(V_{e / m}\right)$ between experimentally determined polycondensation degree and maximal theoretical polycondensation degree under the conditions of monomer excess for different glutamic acid derivatives polycondensation degree, as a result of high polydispersity of the sample (see sample 15, Table 1). High polydispersity and low polycondensation degree is observed at $278 \mathrm{~K}$. It can be concluded that the optimal temperature range for DCC-activated polycondensation of $\mathrm{N}$-substituted glutamic acids and glycols is 283-291 K. In this temperature range the highest polycondensation degrees were achieved.

A nature of glutamic acid protective group is another factor affecting polycondensation reaction. The data shown in Figs. 3 and 4 illustrate that among the studied protected acids only $\mathrm{Glu}(\mathrm{St})$ and $\mathrm{Glu}(\mathrm{L})$, which have large acyl, fragments allow to achieve high polycondensation degrees (75-85\% of the possible value). In contrast, acyl protective group, which is similar by its nature, does not allow to achieve such polycondensation degrees. It should be noted that for all studied labile protective groups - TFA, Boc and Acetyl only $40-55 \%$ from the possible polycondensation degree were achieved. However, application of phthaloyl protective group does not allow even to carry out the polycondensation reaction above $10 \%$ polycondensation degree. Value $V_{e / u}$ for all polyester samples is higher than the value $V_{e / m}$. At the same time, their difference is statistically significant. Only for several polymer samples the determined polycondensation degree is $50-70 \%$ of the values predicted by Carothers equation and just for $\mathrm{Glu}(\mathrm{St})$ and $\mathrm{Glu}(\mathrm{L})$ at the optimal conditions (excess of carboxylic groups and the temperature of the process about $288 \mathrm{~K}) V_{e / u}$ value is approaching 0.9-0.95. As it has been mentioned above, low $V_{e / u}$ value indicates that the processes which lead to the DCU releasing and no polycondensation degree increasing takes place in the system.

The formation of intramolecular bond involving carboxylic group according to scheme in Fig. 5 could be corresponded to such process.

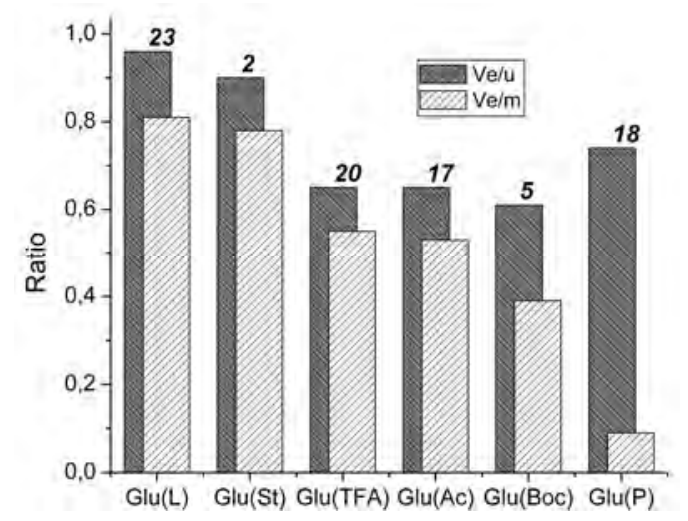

Fig. 4. The ratios $\left(V_{e / m}\right)$ between experimentally determined and maximal theoretical polycondensation degrees and the ratio $\left(V_{e / u}\right)$ between experimentally determined polycondensation degree and polycondensation degree calculated by Eq. (1) considering DCU conversion 


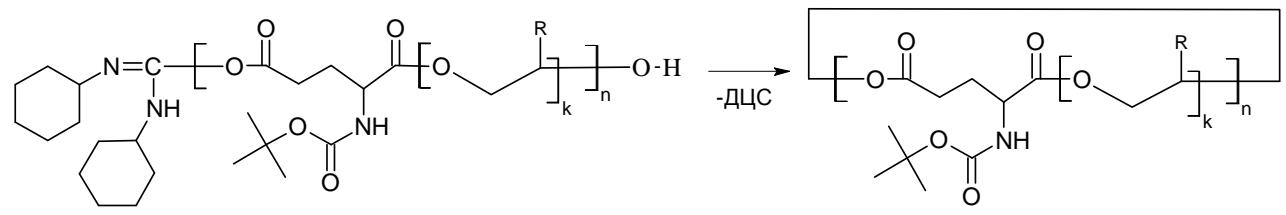

Fig. 5. Side reaction of intramolecular cyclization

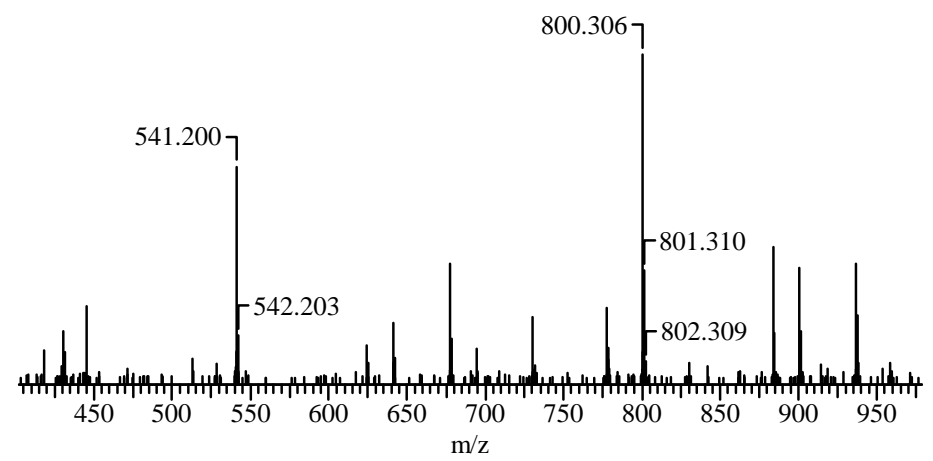

Fig. 6. Fragment of mass-spectrum of the product of Glu(Ac) and DEG polycondensation

As the result of such reaction the DCU releasing could be observed, but the further polymer chain growth under Steglich reaction is not possible. To study the intramolecular cyclization process polyesters based on Glu(Ac) and diethylene glycol (DEG) have been synthesized. To increase probability of intramolecular cycles formation model synthesis were carried out in diluted solutions. After DCU removing products were cleaned using standard procedure and mass spectra for the series of experiments were recorded. Typical mass spectrum is shown in Fig. 6 .

The presence of intensities with $\mathrm{m} / \mathrm{z} 541.200$ and 800.306 in the presented mass spectrum confirms the presence in the reaction mixture of significant amount of cyclic polyesters with the polycondensation degree 2-3.

\subsection{Surface-Active and Colloidal Properties of Glutamic Acid Based Polyesters}

Colloidal properties of synthesized polyesters strongly depend on their composition. Thus polyesters $\mathrm{Glu}(\mathrm{HCl})-\mathrm{PEG}$ or $\mathrm{Glu}(\mathrm{HCl})-\mathrm{PPG}$ with primary amino groups (formed via Boc group removal from corresponding Boc- derivatives) are water soluble at different lengths of glycols $(100-600 \mathrm{~g} / \mathrm{mol})$. Water solutions of such polymers do not possess surface-active properties even at high polymer concentrations. On the other hand polyesters synthesized using $\mathrm{Glu}(\mathrm{St})$ and PEG or PPG with the length below $600 \mathrm{~g} / \mathrm{mol}$ are water insoluble. Such polyesters are not able to form stable selfstabilized dispersions in water and have no ability to decrease surface tension on water-air interface. Only
co-Glu(Ac)-co-DEG (synthesized via polycondensation of Glu(Ac) and diethylenglycol (DEG)) among this type of polymers shows significant surface activity and selfstabilized water dispersions. This copolymer forms stable water dispersion with surface tension $47-49 \mathrm{mN} / \mathrm{m}$. The last demonstrates that surface-active properties and ability of water dispersion to stabilize itself can be provided via hydrophilic/lipophilic fragments ratio in polymer chain. Thus surface active $\mathrm{Glu}(\mathrm{St})$-based polyesters were obtained via simultaneous polycondensation of $\mathrm{Glu}(\mathrm{St})$ with a mixture of PEG and PPG of different molecular weights (Fig. 7).

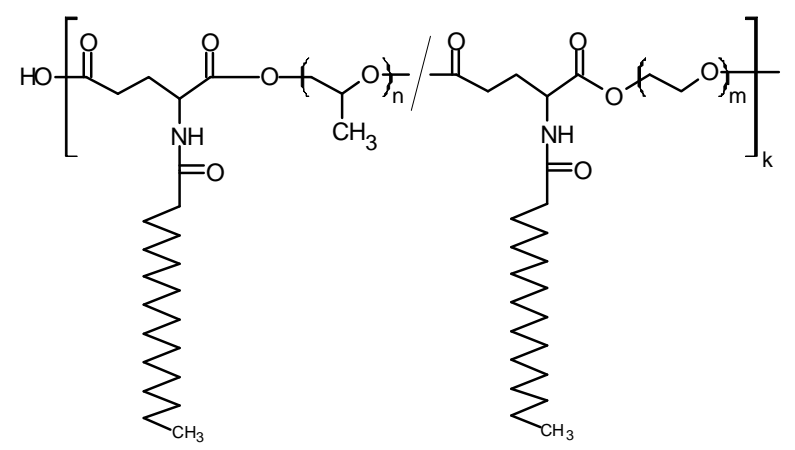

Fig. 7. Schematic structure of polyester synthesized via polycondensation of $\mathrm{Glu}(\mathrm{St})$ with a mixture of equal quantities of PEG and PPG

Two different diols and their part in macromolecule structure were confirmed by NMR-spectroscopy. Large majority of polyesters with different diols are able to form self-stabilized water dispersions. Such polyesters show higher surface activity than polyester molecules with one type of alcohol (Fig. 8). 


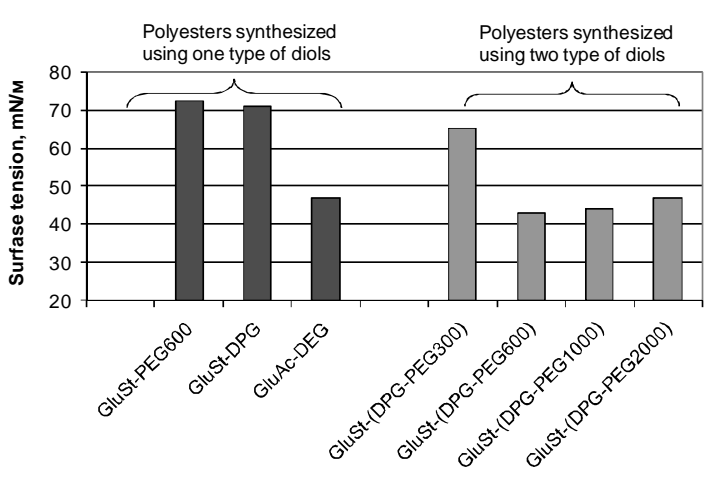

Fig. 8. Surface-active properties of polyesters synthesized via different methods

Copolymers synthesized via simultaneous polycondensation of Glu(St) with the PEG-PPG mixture exhibit higher surface activity and self-stabilization ability. However, their properties significantly depend on the polymer composition. Thus, copolymer made of $\mathrm{Glu}(\mathrm{St})$ and dipropylene glycol / PEG mixture (Glu(St)(DPG-PEG300)) decreases surface tension of water insignificantly (to $63-67 \mathrm{mN} / \mathrm{m}$ ) and forms self-stabilized dispersion only at concentrations below $0.01-0.02 \%$. Copolymer Glu(St)-(DPG-PEG600) decreases surface tension of water to $44 \mathrm{mN} / \mathrm{m}$ and forms self-stabilized dispersion only at concentrations below $0.06 \%$. The following members of this series - Glu(St)-(DPGPEG1000) and Glu(St)(DPG-PEG2000) form colloidally stable dispersions below 4-5\%. The surface tension isotherms for these copolymers are shown in Fig. 9.

A characteristic feature of these isotherms is the presence of two inflection points. First inflection point (in the region of lower concentrations) should be referred to critical micelle concentration $(\mathrm{CMC1})$ and the second inflection point (CMC2) corresponds to some rearrangements of disperse system.

The CMC1 and CMC2 values for the synthesized polyesters are shown in the Table 2.
Table 2

CMC1 and CMC2 values for polyesters synthesized via simultaneous polycondensation of $\mathrm{Glu}(\mathrm{St})$ with the PEG-DPG mixture

\begin{tabular}{|l|c|c|}
\hline & CMC1 & CMC2 \\
\hline Glu(St)-(DPG-PEG600) & 0.0012 & 0.011 \\
\hline Glu(St)-(DPG-PEG1000) & 0.0064 & 0.063 \\
\hline Glu(St)-(DPG-PEG2000) & 0.0134 & 0.103 \\
\hline
\end{tabular}

From the data presented a characteristic relationship can be found - increase in PEG length leads to increasing of $\mathrm{CMC} 1$ and $\mathrm{CMC} 2$ values. Furthermore, in this series the self-stabilizatoin ability has increased as well. Besides, several specific features in polymers properties have been observed. For Glu(St)-(DPGPEG300) hydrophobic properties are predominant (polymer does not decrease water surface tension; low self-solubilization concentration). In contrast, Glu(St)(DPG-PEG600) shows extremely lower surface tension and the concentration of self-solubilized dispersion insignificantly increases. Finally, Glu(St)-(DPGPEG1000) allows to form self-stabilized dispersions in the wide range of concentrations with the lower surface tension values.

Further increase of PEG length in this polyester series leads to the domination of hydrophilic properties. This polyester is capable of forming self-stabilized dispersions with high polymer concentration, however the slight increase of surface tension was observed.

As it was mentioned above, the second inflection point can refer to the some rearrangements of disperse system with increasing of polymer concentration. Size distribution curves of the sample (Glu(St)-DPG-PEG1000) at different concentrations, obtained using dynamic light scattering (DLS), is presented in Fig. 10.

Histograms were obtained at concentrations of $0.02 \%$ (refer to the region after the first inflection point on the surface tension isotherm), $0.05 \%$ (refer to the
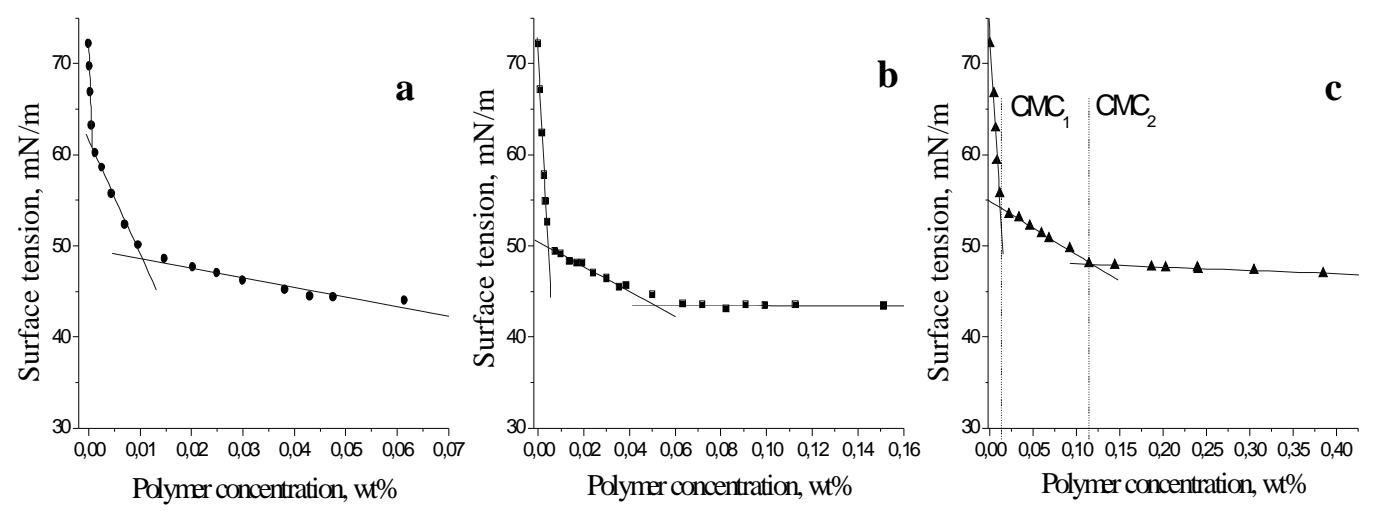

Fig. 9. The surface tension isotherms for Glu(St)-based copolymers 


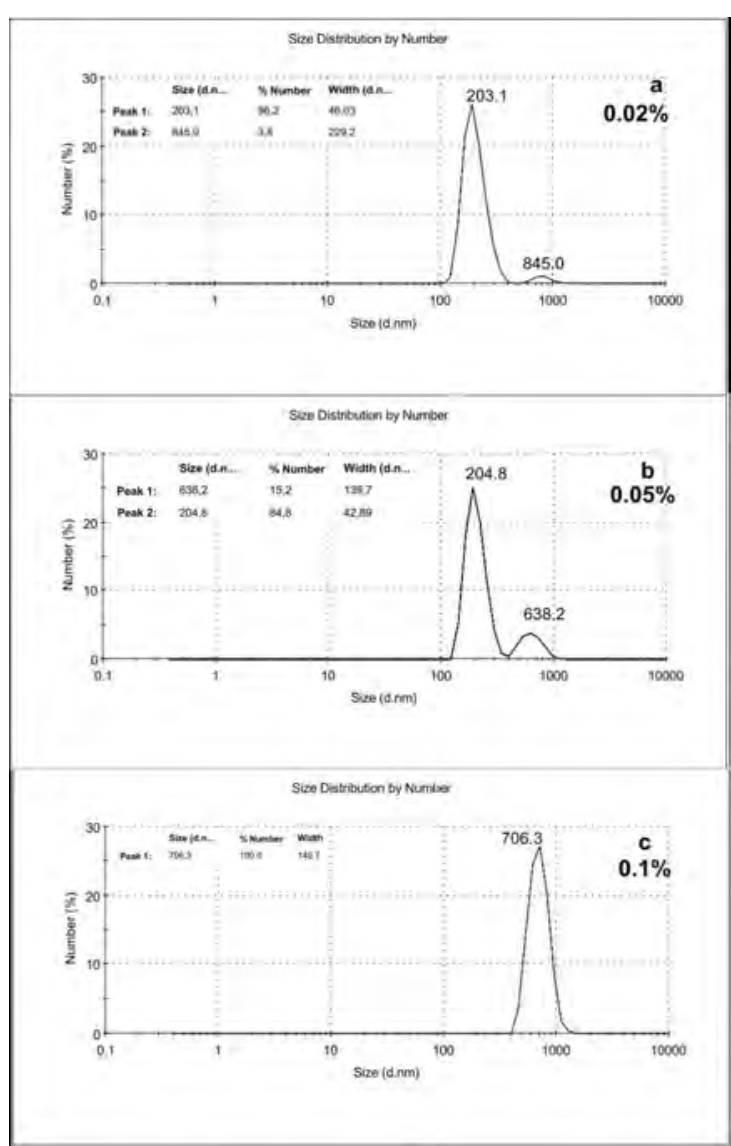

Fig. 10. Size distribution curves of the sample (Glu(St)-DPG-PEG-1000) obtained using DLS method

concentration before the second inflection point on the surface tension isotherm) and $0.1 \%$ (this concentration is located after the second inflection point). Size distribution for the first two concentrations has bimodal character. This indicates the presence of two types of particles in disperse phase. Particles with average diameter $200 \mathrm{~nm}$ dominate numerically. The second mode consists of particles with diameter of $600-850 \mathrm{~nm}$. Number of particles with intermediate size is insignificant. Thus, primary particles with average size $200 \mathrm{~nm}$ consecutively but in an organized way rearrange in particle with larger size. This is confirmed by the following fact - number of particles referring to the first mode makes $5 \%$ at concentration $0.02 \%$ and $15-20 \%$ - at concentration $0.05 \%$. The rearrangement of disperse phase finishes at concentration referring to the second inflection point on the surface tension isotherm. Size distribution curve at disperse phase concentration higher than $0.063 \%$ (the second inflection point) has unimodal character and average diameter refers to the particle size of the second mode on previous curves. It should be noted that disperse systems with disperse phase concentration higher than concentration of the second inflection point maintain colloidal stability.

\section{Conclusions}

Steglich esterification widely used for lowmolecular ester synthesis was successfully used for polyesterification. We managed to obtain pseudopoly(amino acid)s of polyester type based on dicarboxilic amino acids and polyoxypropilene and poluoxyethylene glycols. In case of polyesterification Steglich reaction is sophisticated by the side processes and the highest polycondensation degrees have been obtained using $\mathrm{N}$-derivatives of glutamic acid with volumetric substitutes.

The properties of the obtained polymers can be controlled by polyester composition. Both water soluble and insoluble polymers were synthesized using the developed technique. At certain composition water insoluble polyesters possess surface active properties and are able to form colloidal stable dispersions. Design of polyester-type pseudo-poly(amino acids) able to stabilize itself in water media has been achieved by combination of soft hydrophilic (PEG), soft hydrophobic (PPG) and rigid hydrophobic (Stearoyl) segments.

\section{References}

[1] Jeong B., Bae Y., Lee D. et al.: Nature, 1997, 388, 860.

[2] Holland S., Tighe B. and Gould P.: J. Contr. Release, 1986, 4, 155.

[3] Jeong S. and Kim S.: Arch. Pharm. Res., 1986, 9, 63.

[4] Uhrich K., Cannizzaro S., Langer R. and Shakesheff K.: Chem. Rev., 1999, 99, 3181.

[5] Yokoyama M., Miyauchi M., Yamada N. et al.: Cancer Res., 1990, 50, 1693.

[6] Bae Y. and Kataoka K.: Adv. Drug Deliv. Rev., 2009, 6, 768.

[7] Li Y. and Kwon G.: Colloids Surf. B, 1999, 16, 217.

[8] Lavasanifar A., Samuel J. and Kwon G.: Adv. Drug. Deliv. Rev., $2002, \mathbf{5 4}, 169$.

[9] Guan H., Xie Z., Zhang P. et al.: Biomacromolecules, 2005, 6, 1954.

[10] Puzko N., Varvarenko S., Tarnavchyk I. et al.: Visnyk Nats. Univ. "Lvivska Politechnika", 2011, 700, 364.

[11] Borzenkov M., Dolynska L., Kochubei V. et al.: Chem. \& Chem. Techn., 2011, 5, 363.

[12] Lele B., Gore M. and Kulkarni M.: Synth. Commun., 1999, 29, 1727.

\section{СИНТЕЗ ТА КОЛОЇДНІ ВЛАСТИВОСТІ ПОЛІЕСТЕРІВ НА ОСНОВІ ГЛУТАМІНОВОӤ КИСЛОТИ ТА ГЛІКОЛІВ РІЗНОЇ ПРИРОДИ}

Анотація. Описано синтез та колоїдні властивості нових поліестерів на основі $\alpha$-амінокислоти з контрольованим гідрофільно-ліпофільним балансом. Поліестери на основі глутамінової кислоти та гліколів різної природи одержували внаслідок низькотемпературної активованої поліестерифікачії. Такі полімери здатні формувати міцелярні структури у самостабілізованих водних дисперсіях. Встановлені особливості реакції Стегліха у випадку поліестерифікації та оптимальні умови для синтезу поліестерів.

Ключові слова: псевдо-поліамінокислота, естерифікачія Стегліха, поверхневий натяг, система доставки ліків. 